\title{
Remnants of native forests support carnivore diversity in the vineyard landscapes of central Chile
}

\author{
Camila B. García, Gabriella L. Svensson, Camila Bravo \\ María I. Undurraga, Javiera Díaz-Forestier, Karina Godoy \\ Alexander Neaman, Olga Barbosa, Sebastín Abades and Juan L. Celis-Diez
}

\begin{abstract}
Carnivores play an important role in ecosystem functioning as apex predators. However, most carnivore species are threatened or have been extirpated in humandominated landscapes. The Mediterranean region of central Chile is a biodiversity hotspot, but expansion of agricultural areas such as vineyards is degrading wildlife habitat. We estimated the species richness and composition of carnivore communities in remnant fragments of sclerophyllous forestshrubland in the vineyard landscapes of central Chile to evaluate the effects of human disturbance at different spatial scales. We tested two hypotheses: (1) vineyard landscapes with higher levels of human disturbance support a lower diversity of native carnivores in fragments of remnant native vegetation compared to landscapes with larger areas of natural habitat, and (2) habitat specialists and generalists respond differentially to human influence at the habitat vs landscape spatial scale. We used camera traps at 12 sites across the study area and evaluated the impact of human disturbance indicators on the richness and detection frequency of carnivore species. We found that human population density negatively affected carnivore richness and was associated with a lower detection frequency of the Vulnerable guiña Leopardus guigna. The presence of domestic dogs also had a negative effect on the detection frequency of the guiña and the two native species of foxes, the culpeo Lycalopex culpaeus and South American grey fox
\end{abstract}

Camila B. Garcia, Alexander Neaman (1D orcid.org/0000-0002-1819-0872) and JuAN L. Celis-Diez (Corresponding author, (1) orcid.org/0000-0001-6356-264X) Escuela de Agronomía, Pontificia Universidad Católica de Valparaíso, Valparaíso 2340000, Chile. E-mail juan.celis@pucv.cl

Gabriella L. Svensson Gerencia de Áreas Silvestres Protegidas del Estado, Corporación Nacional Forestal, Santiago, Chile

Camila Bravo Departamento de Ciencias Ecológicas, Universidad de Chile, Santiago, Chile

María I. UndurRaga Instituto de Ecología y Biodiversidad, Santiago, Chile

Javiera Díaz-Forestier Centro Regional de Innovación Hortofrutícola de Valparáiso, Pontificia Universidad Católica de Valparaíso, Quillota, Chile

Karina Godoy* and Olga Barbosa* (D) orcid.org/0000-0001-9397-0070) Instituto de Ciencias Ambientales y Evolutivas, Universidad Austral de Chile, Valdivia, Chile

Sebastián Abades (1D orcid.org/0000-0001-5704-4037) GEMA Center for Genomics, Ecology \& Environment, Facultad de Ciencias, Universidad Mayor, Santiago, Chile

*Also at: Instituto de Ecología y Biodiversidad, Santiago, Chile

Received 26 July 2018. Revision requested 17 September 2018.

Accepted 8 February 2019. First published online 30 January 2020.
Lycalopex griseus. We conclude that protecting remnants of native forest in vineyard landscapes is crucial for carnivore conservation in central Chile.

Keywords Agricultural landscapes, carnivores, Chile, domestic dogs, guiña, Leopardus guigna, sclerophyllous forest, vineyards

Supplementary material for this article is available at doi.org/10.1017/So030605319000152

\section{Introduction}

Carnivores play an important role in the functioning of natural ecosystems as apex predators (Miller et al., 2001). However, anthropogenic activities such as agricultural and urban expansion resulting in habitat loss and degradation, introduction of invasive species, and hunting, threaten carnivores and put them at risk of extinction (Purvis et al., 2000; Crooks, 2002; Farris et al., 2015). Decreases in carnivore populations can lead to changes in abundance of other species through trophic cascade effects (Duffy, 2002). For example, through the consumption of rodents, carnivores indirectly control the transmission of parasites between animals and humans and limit the spread of zoonotic diseases (Ostfeld \& Holt, 2004). Carnivores also act as umbrella species in conservation because they require large areas of suitable habitat to maintain viable populations. Protecting areas large enough to support carnivore populations is likely to benefit many other species and natural communities with smaller habitat requirements (Noss et al., 1996; Thorne et al., 2006). The expansion of human-modified landscapes and resulting habitat loss have led to more frequent interactions between humans and wild carnivores (Randa \& Yunger, 2006; Schüttler et al., 2017), with negative consequences such as increasing competition for food resources and transmission of diseases from domestic dogs to wild predators (Silva-Rodríguez et al., 2010; Acosta-Jamett et al., 2011; Moreira-Arce et al., 2015). Carnivores are also at risk from road traffic and retaliatory killings in response to poultry and livestock depredation (Sanderson et al., 2002; Inskip \& Zimmermann, 2009; Farris et al., 2015). 
Population-level responses to habitat loss can vary amongst carnivore species depending on whether they are habitat generalists or specialists (Acosta-Jamett \& Simonetti, 2004; Zúñiga et al., 2009). Forest specialists such as the guiña Leopardus guigna, for example, are more affected by habitat fragmentation than habitat generalists (Acosta-Jamett \& Simonetti, 2004; Gálvez et al., 2013, 2018; Schüttler et al., 2017). The responses of different carnivore populations also vary depending on the spatial and temporal scale of anthropogenic disturbances (Lyra-Jorge et al., 2010; Moreira-Arce et al., 2015, 2016).

Covering $18 \%$ of the Chilean continental territory, the Mediterranean region of central Chile is considered a biodiversity hotspot because of its high proportion (c. 50\%) of endemic flora and fauna (Myers et al., 2000). The area is dominated by the sclerophyllous forest-shrubland ecosystem (Dinerstein et al., 1995), which is degraded and threatened as a result of historical and ongoing land-use change to agriculture and forestry (Armesto et al., 2010; Schulz et al., 2010). These changes include the recent expansion of avocado plantations and vineyards that is driven by high global demand for these products (Armesto et al., 2010). Approximately 345,000 ha of sclerophyllous forestshrublands remain, with only $2 \%$ (7,000 ha) under protection by the National System of Protected Wild Areas. The drastic loss of habitat since the late 2oth century, with an average net annual deforestation rate of $1,7 \%$ (Armesto et al., 2010; Schulz et al., 2010), is a major challenge for the conservation of vertebrates in central Chile, with almost $30 \%$ of all vertebrate species, including all species of carnivores, currently considered threatened with extinction (Simonetti, 1999).

Protected areas in central Chile are scarce (Armesto et al., 1998; Castañeda et al., 2015), small and disconnected (Simonetti \& Mella, 1997; Simonetti, 1999). Because carnivores require large areas of suitable habitat (Noss et al., 1996; Sanderson et al., 2002; Thorne et al., 2006) and cannot persist solely in small protected areas (Acosta-Jamett \& Simonetti, 2004; Zúñiga et al., 2009; Gálvez et al., 2013), remnant fragments of native vegetation preserved in privately owned and productive areas (e.g. within the rural or agriculture landscape) are increasingly important for their conservation. Together with less intensive agriculture and land-use changes, such habitat patches and vegetation corridors improve connectivity and facilitate movement amongst native forest remnants, thus increasing habitat availability within agricultural landscapes and supporting the conservation of carnivores (Acosta-Jamett \& Simonetti, 2004; Hilty \& Merenlender, 2004; Pita et al., 2009; Gálvez et al., 2013; Nogeire et al., 2013; Schüttler et al., 2017).

In the forestry landscapes of southern Chile the guiña, a habitat specialist, occurs mostly in native forests (AcostaJamett \& Simonetti, 2004; Zúñiga et al., 2009), whereas the culpeo Lycalopex culpaeus, South American grey fox
Lycalopex griseus, cougar Puma concolor and lesser grison Galictis cuja, which are all habitat generalists, are more frequently observed in open habitats and exotic pine plantations (Acosta-Jamett \& Simonetti, 2004; Zúñiga et al., 2009). In temperate rainforest of southern Chile the guiña is negatively affected by forest fragmentation (Gálvez et al., 2018), and the conservation of native forest remnants is thus important for its conservation (Gálvez et al., 2013; Schüttler et al., 2017). However, to our knowledge no research has been conducted in the Mediterranean region of central Chile, where agricultural landscapes dominate. In northern hemisphere farmlands with a Mediterranean climate that include semi-natural habitats, vegetation corridors and forest remnants support a higher diversity and abundance of carnivores compared to intensively farmed fields (Pita et al., 2009).

We hypothesized that (1) vineyard landscapes with higher levels of human disturbance support a lower diversity of native carnivores in remnant native vegetation compared to vineyard landscapes with more natural habitat, and (2) habitat specialists and generalists respond differentially to human disturbance at the habitat and landscape spatial scale. We therefore (1) estimated wild carnivore diversity in remnants of sclerophyllous forest-shrublands in the vineyard landscapes of central Chile, and (2) evaluated the effects of variables representing human disturbance at different spatial scales on the wild carnivores inhabiting this area.

\section{Methods}

\section{Camera-trap survey}

During 2013-2016 we installed 53 camera traps (Trophy Cam HD, Bushnell, Overland Park, USA) in 12 remnant patches of sclerophyllous forest-shrublands (4-8 cameras per site) in vineyard landscapes in the Mediterranean region of central Chile (Fig. 1). Camera traps were at a distance of $<400 \mathrm{~m}$ from a vineyard and baited with three pieces of fresh chicken and lynx urine (Wildlife Control Supplies, East Granby, USA) to increase the detection of carnivores (Silva-Rodríguez et al., 2018). We fixed cameras to tree trunks $30 \mathrm{~cm}$ above the ground facing south, to minimize false triggers from the rising or setting sun, with a distance of at least $300 \mathrm{~m}$ (mean 2,042.4 \pm SD $962.8 \mathrm{~m}$ ) between cameras at a site. Cameras recorded date and time of each picture captured, and the movement sensor was set to medium sensitivity. Cameras remained active continuously for 30 days and the total camera-trapping effort was 1,590 days (53 cameras $\times 30$ days).

We identified carnivores using specialized literature (Iriarte \& Jaksic, 2012) and our own field experience. We calculated the detection frequency for each species based on 


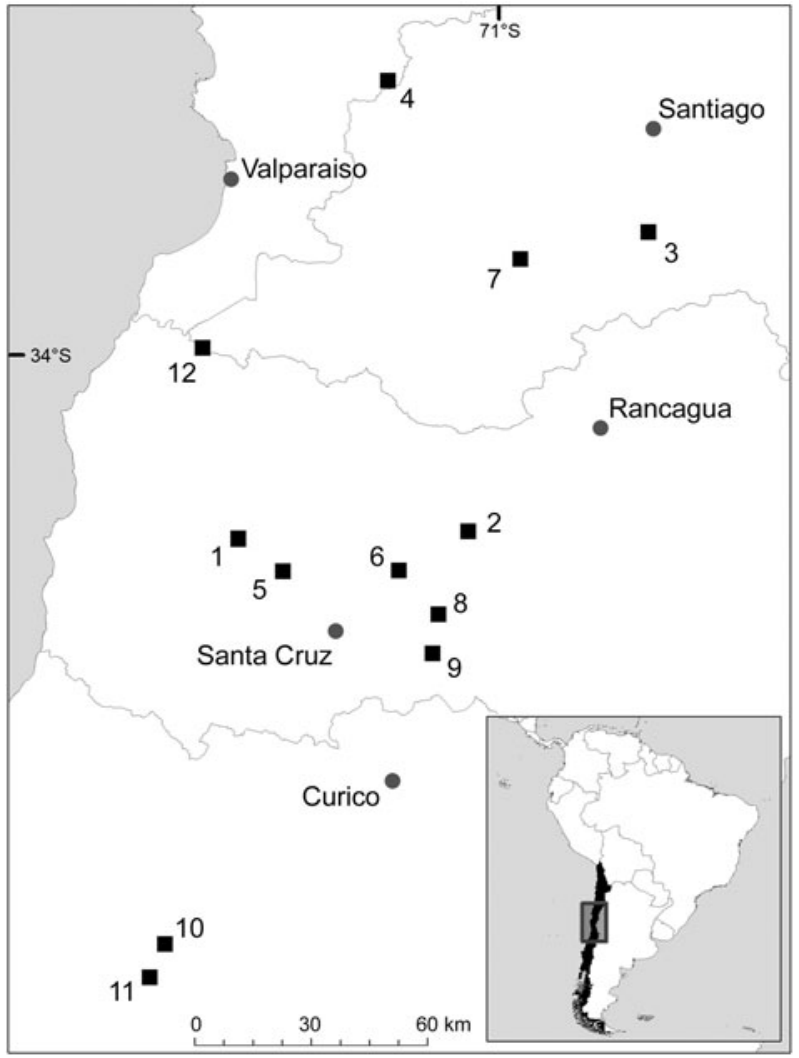

FIG. 1 Location of the 12 study sites in the vineyard landscape of central Chile.

the number of independent photographic records on each camera trap during the 30-day sampling period. To determine the number of independent records we followed the methodology proposed by Medellín et al. (2006), which has been applied in several studies (Monroy-Vilchis et al., 2011; Lira-Torres \& Briones-Salas, 2012). Consecutive photographs were counted as independent records if they showed different identifiable individuals (distinguished by marks such as fur colouring pattern or scars), or after an interval of 24 hours when we could not determine whether a series of consecutive photographs of the same species showed the same individual. Non-consecutive photographs of the same species were also counted as independent records. We considered the number of records to represent animal activity and a proxy for animal abundance (sensu Silva-Rodríguez et al., 2018). We used previous literature to categorize carnivore species as habitat generalists or specialists.

\section{Carnivore richness}

Using the independent photographic records of each camera trap, we estimated species richness (i.e. the total number of species detected) and detection frequency of each species. We assessed dissimilarity of carnivore richness between sites using the Morisita-Horn index (Wolda, 1981) with functions available in package vegan (Oksanen et al., 2016) for $R$ 3.4.4 (R Core Team, 2018).

\section{Habitat characterization}

We evaluated the effect of habitat characteristics on carnivores at two spatial scales: (1) at the local habitat level, defined as the area within a circular plot with a radius of $200 \mathrm{~m}$ around each camera trap (i.e. within sites), and (2) at the landscape level, defined as the area within circular plots of 1,5 and $10 \mathrm{~km}$ radius from the centroid of the camera traps at each site. At each scale the land-use type of the surrounding vineyard landscape was characterized using the naturalness evaluation index (NEI; Baiamonte et al., 2015), which assesses different land uses according to the degree of human disturbance, using the formula:

$$
\mathrm{NEI}=\frac{(C 1+2 C 2+3 C 3)}{(3(C 0+C 1+C 2+C 3))}
$$

where $C o$ is an area with high levels of human disturbance, $C_{1}$ is an agricultural area, $C_{2}$ is a semi-natural and $C_{3}$ is a natural area.

For this index we defined different levels of anthropogenic modification as (1) areas with high human impact such as urban and industrial areas, (2) agricultural areas such as arable farms, vineyards and forest plantations, (3) semi-natural areas such as scrubland dominated by wild exotic species (e.g. Acacia dealbata, Teline monspessulana), and (4) natural areas such as native forest-shrublands and wetlands.

We assessed land use at the landscape level using the Native Forest Inventory of the National Forestry Corporation of Chile (CONAF, 2016), including the regions of Valparaiso, O'Higgins, El Maule and the Metropolitan Region. We analysed the data using ArcGIS 10.1 (Esri, Redlands, USA). At the habitat level we analysed land use with a Quickbird 2014 satellite image from Google Earth Pro (Google, 2016).

At each site we assessed the human influence on carnivore richness using the variables human population (the number of inhabitants per district; data from INE, 2017), minimum distance to urban areas or roads, and distance to the nearest protected area. Additionally, at the habitat scale (i.e. within sites) we evaluated the effects of the detection frequency of domestic dogs and habitat complexity, the latter estimated by the Shannon-Wiener index derived from the land-use data associated with each camera trap.

\section{Statistical analysis}

To assess the effect of human disturbance on species richness at the landscape and habitat scales we used a generalized linear mixed model (Burnham \& Anderson, 2002). 
Predictor variables included factors measured at the landscape level, factors common to each site and factors measured at the habitat level (i.e. at the level of individual camera traps). The generalized linear mixed model was fit assuming a Poisson distribution of errors, because the response variable (i.e. number of species detected) is a count. Additionally, we evaluated the effect of human disturbance on the detection frequency of habitat specialist and generalist native carnivores. We considered both fox species (culpeo and grey fox) and the grison habitat generalists, and the guiña, pampas cat Leopardus colocolo and Molina's hog-nosed skunk Conepatus chinga habitat specialists (Acosta-Jamentt \& Simonetti, 2004; Guzmán-Sandoval et al., 2007; Zúñiga et al., 2009). We only considered species with sufficiently high detection frequencies to support model fitting, excluding species with $<10$ records (pampas cat, Molina's hog-nosed skunk and lesser grison).

The fixed model factors measured at the landscape level were the naturalness evaluation indices estimated for the 1,5 and $10 \mathrm{~km}$ radius buffers around the centre of camera-trap sites, human population of the district in which the site was located, minimum distance to urban areas, minimum distance to roads and minimum distance to the nearest protected area. At the habitat level, the fixed factors were the naturalness evaluation index estimated within a $200 \mathrm{~m}$ radius around each camera trap, the detection frequency of domestic dogs and habitat complexity. Random factors of the mixed model were the vineyard near which the camera trap was located (i.e. the site) and the survey year.

Fixed effects were $z$-standardized because they were measured in different units and a common scale of analysis facilitates comparison of the relative contribution of each predictor variable in the model (Schüttler et al., 2017). To initialize the model selection procedure, we specified a global model containing all possible predictors for the fixed part of the mixed model. The best model was then selected from a large number of subset models generated using the dredge function in the $R$ package MuMIn (Barton, 2018). Using an Akaike information criterion (AIC) approach, we selected the best model based on the lowest AIC value.

We evaluated the collinearity between the predictor variables using variance inflation factors (accepted threshold $<_{3}$ ), with the $R$ packages lme4 (Bates et al., 2015) and MuMIn (Barton, 2018), and evaluated the variance inflation factors function based on Zuur et al. (2009).

Finally, we determined the effects of human disturbance on carnivore composition at the site level (i.e. each vineyard) through PERMANOVA analysis using Adonis 2 (Oksanen et al., 2016) with 999 permutations. The response variable was the matrix of distances generated using the Horn method based on a matrix of carnivore detection frequencies, including native and exotic species. The co-variables used in this analysis were the naturalness evaluation indices estimated at 1,5 and $10 \mathrm{~km}$, and the human population of the district in which the site was located. This analysis was carried out using the $R$ package vegan (Oksanen et al., 2016).

\section{Results}

We obtained 406 independent photographic records of carnivores from a total of c. 25,000 camera-trap photographs. We identified eight carnivore species, six of which were native and two exotic. Amongst the native carnivores, the guiña is considered Vulnerable, the pampas cat Near Threatened, Molina's hog-nosed skunk Rare, and the two foxes and the grison are of Least Concern according to national categorization (Ministerio del Medio Ambiente, 2012), which is based on the IUCN Red List categories and the Chilean hunting law (Ministerio de Agricultura, 1998; Table 1).

The South American grey fox was the most frequently detected species (33\% of all records), followed by the culpeo with $24 \%$, the exotic domestic dog Canis lupus familiaris with $20 \%$ and the guiña with $17 \%$ (Table 1 ). The native pampas cat, Molina's hog-nosed skunk and grison, and the exotic domestic cat Felis catus together accounted for $<5.5 \%$ of all records (Table 1 ), with the pampas cat being the least frequently recorded species, with only a single record (Supplementary Table 1).

The generalized linear mixed models indicated that human population of the district in which the site was located has a negative influence on native carnivore richness (Table 2), whereas the random effect variances for the grouping factors vineyard and year were close to zero.

The detection frequencies of both habitat generalists (foxes) and specialists (the guiña) were negatively influenced by an increased presence of domestic dogs (Table 3 ). Human population and a higher degree of naturalness of the landscape at the $10-\mathrm{km}$ scale also negatively influenced the detection frequency of the guiña, whereas a higher naturalness index on a $5-\mathrm{km}$ scale had a small but significant positive influence (Table 3).

The PERMANOVA analysis showed that none of the parameters significantly influenced the composition of carnivore communities between different vineyards (Table 4).

\section{Discussion}

Our camera traps recorded almost all wild carnivore species occurring in the Mediterranean region of Chile (Iriarte \& Jaksic, 2012), except for the cougar, in the vicinity of vineyards. This highlights the importance of remnants of native vegetation for carnivore conservation in agricultural landscapes.

The most frequently recorded species were the culpeo and South American grey fox. Their presence in humandominated landscapes could be related to their omnivorous diets (Guzmán-Sandoval et al., 2007). The guiña was the 
TABLE 1 Origin, conservation status and detection frequency (\%) of carnivores recorded in the sampled vineyards of central Chile.

\begin{tabular}{|c|c|c|c|c|}
\hline Family & Species & Origin & Conservation status ${ }^{1}$ & Detection frequency (\%) \\
\hline Canidae & Lycalopex griseus & Native & Least Concern & 33.3 \\
\hline Canidae & Lycalopex culpaeus & Native & Least Concern & 24.1 \\
\hline Canidae & Canis lupus familiaris & Exotic & & 20.4 \\
\hline Felidae & Leopardus guigna & Native & Vulnerable & 16.7 \\
\hline Mustelidae & Galictis cuja & Native & Least Concern & 2.5 \\
\hline Mephitidae & Conepatus chinga & Native & Rare & 1.7 \\
\hline Felidae & Felis catus & Exotic & & 1.0 \\
\hline Felidae & Leopardus colocolo & Native & Near Threatened & 0.2 \\
\hline
\end{tabular}

${ }^{1}$ According to Ministerio del Medio Ambiente (2012).

TABLE 2 Results of linear regression analysis for the relationship between the number of carnivore species detected in vineyard landscapes (12 surveyed sites) in central Chile. Predictors are variables selected after applying a best subset model routine to a larger number of candidate variables.

\begin{tabular}{lrrl}
\hline & Estimate $\pm S D$ & $Z$-value & P \\
\hline (Intercept) & $0.3772 \pm 0.117$ & 3.235 & 0.001 \\
Minimum distance to roads & $0.2316 \pm 0.132$ & 1.755 & 0.079 \\
Human population in district & $-0.3072 \pm 0.135$ & -2.281 & 0.023 \\
\hline
\end{tabular}

most frequently observed felid, whereas the pampas cat was recorded only once, probably because it is principally a montane species (Iriarte \& Jaksic, 2012). Contrary to our findings, an approach using species distribution models (Guillera-Arroita et al., 2015) reported a low probability of guiña occurrence in the sclerophyllous forest-shrublands of central Chile (Cuyckens et al., 2015). It is possible that the relatively high detection frequency of guiñas, which are forest specialists (Acosta-Jamett \& Simonetti, 2004), in our study was a result of their movements through remnant forest strips along vineyard borders within rural areas (Schüttler et al., 2017).

In agreement with our first hypothesis, we found that species richness was higher in landscapes with less anthropogenic pressure: higher human population had a negative influence on carnivore richness. However, none of the anthropogenic variables influenced carnivore composition between different vineyard landscapes. This is probably a result of the overall low number of recorded species, and the high detection frequency of only a few of them.

The detection frequency of domestic dogs negatively affected the detection of both habitat generalists (foxes) and specialists (the guiña) in vineyard landscapes. This corroborates previous research in Chile, which found a negative correlation between the abundance of domestic dogs and the abundance of the South American grey fox and Darwin's fox Lycalopex fulvipes (Silva-Rodríguez et al., 2010, 2018; Moreira-Arce et al., 2015), and highlights the importance of managing feral domestic animals in Chile (Bonacic et al., 2019). The negative relationship between domestic and wild canids could be explained by their phylogenetic closeness, which may lead to the transmission of infectious diseases from dogs to foxes (Acosta-Jamett et al., 2011), in addition to competition for prey (Silva-Rodríguez \& Sieving, 2012). Domestic dogs may thus have cumulative effects on native carnivores through resource competition and interference (Vanak \& Gompper, 2009). However, although there is documented evidence of negative effects of dogs on foxes, few studies have reported any mortality of the guiña attributable directly to domestic dogs (Silva-Rodríguez et al., 2007).

Previous studies suggest human disturbance negatively affects native carnivores in southern Chile (Sanderson et al., 2002; Silva-Rodríguez et al., 2009, 2018; Gálvez et al., 2013; Schüttler et al., 2017). The guiña does not avoid human-dominated areas and can fall victim to ecological traps when attracted to human areas by food (Schüttler et al., 2017). Threats to the guiña in humandominated areas include collisions with vehicles and hunting in retaliation for poultry depredation (Sanderson et al., 2002; Silva-Rodríguez et al., 2009; Gálvez et al., 2013).

The proportion of natural areas in the landscape affected the guiña, as shown by the small positive influence of higher naturalness at the $5-\mathrm{km}$ scale on its detection frequency. However, at the $10-\mathrm{km}$ scale we detected a significantly negative influence of this variable. These contrasting findings can be attributed to a bias in the naturalness index that did not consider the degree of fragmentation of the sampled natural areas or any physical barriers to animal movement across private lands (e.g. fences). The guiña is affected by habitat fragmentation resulting from the subdivision of large farms into smaller properties (Gálvez et al., 2018). Further studies of rural landscapes in central Chile should thus consider parcelling of land as a form of habitat fragmentation. In addition, corridors and continuous areas of native vegetation should be retained or created as a common practice to avoid habitat fragmentation in agricultural landscapes.

Our second hypothesis was that the spatial scale of human disturbance affects habitat specialists and generalists carnivores differently. We found that habitat generalists (foxes) were not influenced by the naturalness of the 
TABLE 3 Results of generalized linear mixed model regression analysis for the relationship between the frequency of occurrence of native habitat generalist (foxes L. griseus and L. culpaeus) and specialist (guiña L. guigna) carnivores in surveyed vineyard landscapes of central Chile. The table shows predictors that remained after applying a subset selection routine over a larger number of potential explanatory variables.

\begin{tabular}{llrrr}
\hline Model & Predictor & Estimate \pm SD & $Z$-value & P \\
\hline Habitat generalist $^{1}$ & (Intercept) & $1.2470 \pm 0.1718$ & 7.260 & $3.86 \times 10^{-13}$ \\
& Detection frequency of domestic dogs & $-0.3542 \pm 0.1348$ & -2.628 & 0.00859 \\
Habitat specialist $^{2}$ & (Intercept) & $-1.0208 \pm 0.4481$ & -2.278 & 0.02274 \\
& Detection frequency of domestic dogs & $-0.5126 \pm 0.2571$ & -1.994 & 0.04619 \\
& $\mathrm{NEI}^{3} 10 \mathrm{~km}$ & $-1.9408 \pm 0.6882$ & -2.820 & 0.00480 \\
& $\mathrm{NEI}^{3} 5 \mathrm{~km}$ & $1.0008 \pm 0.5838$ & 1.714 & 0.08647 \\
& Human population in district & $-1.5820 \pm 0.5373$ & -2.944 & 0.00324 \\
\hline
\end{tabular}

${ }^{1}$ Random effect for habitat generalist (SD): Vineyard $=0.5077$; Year $<0.0001$.

${ }^{2}$ Random effect for habitat specialist (SD): Vineyard $=0.6824836$; Year $=0.0002575$.

${ }^{3} \mathrm{NEI}$, naturalness evaluation index.

TABLE 4 Results of PERMANOVA analysis, using the MorisitaHorn index, of dissimilarity of carnivore composition between different sites in vineyard landscapes in central Chile.

\begin{tabular}{lllll}
\hline & df & Sum of squares & $F$ & $\mathrm{P}$ \\
\hline $\mathrm{NEI}^{1} 10 \mathrm{~km}$ & 1 & 0.40258 & 1.9974 & 0.121 \\
$\mathrm{NEI}^{1} 5 \mathrm{~km}$ & 1 & 0.42541 & 2.1107 & 0.091 \\
$\mathrm{NEI}^{1} 1 \mathrm{~km}$ & 1 & 0.32718 & 1.6233 & 0.190 \\
Human population & 1 & 0.45453 & 2.2552 & 0.093 \\
$\quad$ in district & & & & \\
Residual & 7 & 1.41084 & & \\
\hline
\end{tabular}

${ }^{1} \mathrm{NEI}$, naturalness evaluation index.

landscape, whereas habitat specialists (the guiña) were affected. These findings corroborate a previous study that found the scale of spatial analysis influenced the impact of human activity and domestic dogs on native carnivores in southern Chile (Moreira-Arce et al., 2015), suggesting there is an urgent need to control domestic dogs in rural areas to conserve native carnivores (Bonacic et al., 2019).

There is debate regarding the use of photographic detection frequencies as a proxy for abundance (Rovero \& Marshall, 2009), and occupancy models are being used to account for detection probability. This is a limitation of our methodology, because detection rates reflect activity levels rather than abundances. However, our criteria for identifying independent records were more restrictive than those used in previous studies on carnivores (O'Brien et al., 2003; Rovero \& Marshall, 2009; Silva-Rodríguez et al., 2018), which considered photographs as independent events if separated by at least 60 minutes, with the detection frequency termed relative abundance index and used as a proxy for animal abundance (O'Brien et al., 2003). Despite the limitations of the method, to our knowledge this is the first study to assess native carnivore richness and activity in the agricultural area of central Chile. Our results highlight the importance of remnant native forest fragments in vineyard landscapes as potential areas for carnivore conservation, and provide an example of how industries, by preserving natural habitats within their properties, can support biodiversity conservation in productive areas.

Our findings also support the conclusion of a previous study on the importance of remnant patches of native southern temperate rainforest in human-dominated landscapes for the conservation of the guiña (Gálvez et al., 2013). Preservation of sclerophyllous forest-shrublands in rural landscapes of central Chile may not only benefit wildlife populations, but also provide other ecosystem services such as pollination, pest control and water regulation to agricultural areas (Power, 2010; Liss et al., 2013). Farming landscapes are essential for a growing human population, both for the provision of food and the conservation of biodiversity, because they occupy large expanses of land, are often adjacent to critical wildlife habitats and depend on ecosystem services (Viers et al., 2013). Vineyards can benefit from ecosystems services and contribute to biodiversity, particularly as wine producers and consumers place increasing value on the environmental impact of these productive areas (Viers et al., 2013). Wine producers should thus evaluate and implement land management strategies that support biodiversity conservation. Protecting existing forest remnants and increasing the number and width of biological corridors (Hilty \& Merenlender, 2004) could help safeguard the biodiversity of sclerophyllous forest-shrublands. Vintners play an important role in biodiversity conservation: their efforts to preserve and expand native forest remnants on their properties are vital for the conservation of the native fauna of central Chile.

Acknowledgements This study is a contribution to the Wine, Climate Change and Biodiversity Program of the Institute of Ecology and Biodiversity. The study was partially supported by PUCV-DI 039.407/19 and ACT192027 to JLC-D. JLC-D is an affiliated researcher with the Institute of Ecology and Biodiversity, Chile. SA was funded by FONDECYT 1170995. We thank the vineyards Concha y Toro, Veramonte, Santa Rita, San Pedro de Tarapacá, Viu Mannent, Emiliana and Luis Felipe Edwards for their support. 
Author contributions Study design JLC-D, JDF, GLS; fieldwork: GLS, CB, MIU; data analysis: CBG, KG, SA, JLC-D, GLS; writing: JLC-D, CBG, SA, OB, JDF, AN.

\section{Conflicts of interest None.}

Ethical standards This research abided by the Oryx guidelines on ethical standards.

\section{References}

Acosta-Jamett, G. \& Simonetti, J.A. (2004) Habitat use by Oncifelis guigna and Pseudalopex culpaeus in a fragmented forest landscape in central Chile. Biodiversity and Conservation, 13, 1135-1151.

Acosta-Jamett, G., Chalmers, W.S.K., Cunningham, A.A., Cleaveland, S., Handel, I.G. \& Bronsvoort, B.M.D.C. (2011) Urban domestic dog populations as a source of canine distemper virus for wild carnivores in the Coquimbo region of Chile. Veterinary Microbiology, 152, 247-257.

Armesto, J.J., Rozzi, R., Smith-Ramírez, C. \& Arrollo, M.T. (1998) Conservation targets in South American temperate forests. Science, 282, 1271-1272.

Armesto, J.J., Manuschevich, D., Mora, A., Smith-Ramirez, C., Rozzi, R., Abarzúa, A.M. \& Marquet, P.A. (2010) From the Holocene to the Anthropocene: a historical framework for land cover change in southwestern South America in the past 15,000 years. Land Use Policy, 27, 148-160.

Baiamonte, G., Domina, G., Raimondo, F.M. \& Bazan, G. (2015) Agricultural landscapes and biodiversity conservation: a case study in Sicily (Italy). Biodiversity and Conservation, 24, 3201-3216.

Barton, K. (2018) MuMIn: Multi-Model Inference, $R$ Package v.1.40.4. cran.r-project.org/web/packages/MuMIn [accessed 16 September 2019].

Bates, D., Maechle, M., Bolker, B. \& Walker, S. (2015) Fitting linear mixed-effects models using lme4. Journal of Statistical Software, 67, 1-48.

Bonacic, C., Almuna, R. \& Ibarra, J.T. (2019) Biodiversity conservation requires management of feral domestic animals. Trends in Ecology and Evolution, 34, 683-686.

Burnham, K.P. \& Anderson, D.R. (2002) Model Selection and Multimodel Inference: a Practical Information-Theoretic Approach. 2nd edition. Springer, New York, USA.

Castañeda, L.E., Godoy, K., Manzano, M., Marquet, P.A. \& Barbosa, O. (2015) Comparison of soil microbial communities inhabiting vineyards and native sclerophyllous forests in central Chile. Ecology and Evolution, 5, 3857-3868.

CONAF (Corporación Nacional Forestal) (2016) Sistema de Información Territorial. sit.conaf.cl [accessed 20 July 2018].

Croокs, K.R. (2002) Relative Sensitivities of mammalian carnivores to habitat fragmentation. Conservation Biology, 16, 488-502.

Cuyckens, G.A.E., Morales, M.M. \& Tognelli, M.F. (2015) Assessing the distribution of a Vulnerable felid species: threats from human land use and climate change to the kodkod Leopardus guigna. Oryx, 49, 611-618.

Dinerstein, E., Olson, D.M., Graham, D.J., Webster, A.L., Primm, S.A., Bookbinder, M.P. \& Ledec, G. (1995) A Conservation Assessment of the Terrestrial Ecoregions of Latin America and the Caribbean. The International Bank for Reconstruction and Development/The World Bank, Washington, DC, USA.

DUfFY, J.E. (2002) Biodiversity and ecosystem function: the consumer connection. Oikos, 99, 201-219.
Estrada-Carmona, N., Hart, A.K., DeClerck, F.A.J., Harvey, C.A. \& Milder, J.C. (2014) Integrated landscape management for agriculture, rural livelihoods, and ecosystem conservation: an assessment of experience from Latin America and the Caribbean. Landscape and Urban Planning, 129, 1-11.

Farris, Z.J., Golden, C.D., Karpanty, S., Murphy, A., Stauffer, D., Ratelolahy, F. et al. (2015) Hunting, exotic carnivores, and habitat loss: anthropogenic effects on a native carnivore community, Madagascar. PLOS ONE, 10, e0136456.

Gálvez, N., Hernández, F., Laker, J., Gilabert, H., Petitpas, R., BonACIC, C. et al. (2013) Forest cover outside protected areas plays an important role in the conservation of the Vulnerable guiña Leopardus guigna. Oryx, 47, 251-258.

Gálvez, N., Guillera-Arroita, G., St. John, F.A.V., Schüttler, E., Macdonald, D.W. \& Davies, Z.G. (2018) A spatially integrated framework for assessing socioecological drivers of carnivore decline. Journal of Applied Ecology, 55, 1393-1405.

Guillera-Arroita, G., Lahoz-Monfort, J.J., Elith, J., Gordon, A., Kujala, H., Lentini, P.E. et al. (2015) Is my species distribution model fit for purpose? Matching data and models to applications. Global Ecology and Biogeography, 24, 276-292.

Guzmán-Sandoval, J., Sielfeld, W. \& Ferru, M. (2007) Diet of Lycalopex culpaeus (Mammalia: Canidae) in northernmost Chile (Tarapaca Region). Gayana, 71, 1-7.

Google (2016) Google Earth Pro v7.1.7.2606. google.co.uk/earth [accessed 20 July 2018].

Hilty, J.A. \& Merenlender, A.M. (2004) Use of riparian corridors and vineyards by mammalian predators in Northern California. Conservation Biology, 18, 126-135.

ine (Instituto Nacional de Estadísticas) (2017) Censo de Población y Vivienda. INE, Santiago, Chile. censo2017.cl [accessed 10 July 2019].

Inskip, C. \& Zimmermann, A. (2009) Human-felid conflict: a review of patterns and priorities worldwide. Oryx, 43, 18-34.

Iriarte, A. \& Jaksic, F. (2012) Los Carnívoros de Chile. Ediciones Flora \& Fauna Chile y CASEB, Pontificía Universidad Católica de Chile, Santiago, Chile.

Lira-Torres, I. \& Briones-Salas, M. (2012) Abundacia relativa y patrones de actividad de los mamíferos de los Chimalapas, Oaxaca, México. Acta Zoológica Mexicana, 28, 566-585.

Liss, K.N., Mitchell, M.G.E., Macdonald, G.K., Mahajan, S.L., Ме́тнот, J., ЈАСов, A.L. et al. (2013) Variability in ecosystem service measurement: a pollination service case study. Frontiers in Ecology and the Environment, 11, 414-422.

Lyra-Jorge, M.C., Ribeiro, M.C., Ciocheti, G., Tambosi, L.R. \& Pivello, V.R. (2010) Influence of multi-scale landscape structure on the occurrence of carnivorous mammals in a humanmodified savanna, Brazil. European Journal of Wildlife Research, 56, 359-368.

Ministerio de Agricultura (1998) Decreto 5 que Aprueba el Reglamento de la Ley de Caza. Biblioteca del Congreso Nacional de Chile. leychile.cl/Navegar?idNorma $=128106$ [accessed 20 July 2018].

Ministerio del Medio Ambiente (2012) Decreto 29 que Aprueba el Reglamento para la Clasificación de Especies Silvestres Según Estado de Conservación. Biblioteca del Congreso Nacional de Chile. leychile. cl/Navegar?idNorma $=1039460$ [accessed 20 July 2018].

Medellín, R., Azuara, D., Maffei, L., Zarza, H., Bárcenas, H., Cruz, E. et al. (2006) Censos y Monitoreo. In El Jaguar Mexicano en el Siglo XXI: Situación Actual y Manejo (eds C. Chávez \& G. Ceballos), pp. 25-35. CONABIO-Alianza, WWF, Telcel, and Universidad Nacional Autónoma de México, Mexico City, Mexico.

Miller, B., Dugelby, B., Foreman, D., Del Rio, C.M., Noss, R., Phillips, M. et al. (2001) The importance of large carnivores to healthy ecosystems. Endangered Species Update, 18, 202-210. 
Monroy-Vilchis, O., Zarco-González, M.M. \& RodrígueZSoto, C. (2011) Fototrampeo de mamíferos en la Sierra Nanchititla, México. Revista de Biología Tropical, 59, 373-383.

Moreira-Arce, D., Vergara, P.M. \& Boutin, S. (2015) Diurnal human activity and introduced species affect occurrence of carnivores in a human-dominated landscape. PLOS ONE, 10, e0137854.

Moreira-Arce, D., Vergara, P.M., Boutin, S., Carrasco, G., Briones, R., Soto, G.E. \& Jiménez, J.E. (2016) Mesocarnivores respond to fine-grain habitat structure in a mosaic landscape comprised by commercial forest plantations in southern Chile. Forest Ecology and Management, 369, 135-143.

Myers, N., Mittermeier, A.R., Mittermeier, C.G., Fonseca, G.A.B. \& KENT, J. (2000) Biodiversity hotspots for conservation priorities. Nature, 403, 853-858.

Nogeire, T.M., Davis, F.W., Duggan, J.M., Crooks, K.R. \& Boydston, E.E. (2013) Carnivore use of avocado orchards across an agricultural-wildland gradient. PLOS ONE, 8, e68025.

Noss, R.F., Quigley, H.B., Hornocker, M.G., Merrill, T. \& PAQUET, P.C. (1996) Conservation biology and carnivore conservation in the Rocky Mountains. Conservation Biology, 10, 949-963.

O’Brien, T.G., Kinnaird, M.F. \& Wibisono, H.T. (2003) Crouching tigers, hidden prey: Sumatran tiger and prey populations in a tropical forest landscape. Animal Conservation, 6, 131-139.

Oksanen, J., Blanchet, F.G., Friendly, M., Kindt, R., Legendre, P., McGlinn, D. et al. (2016) Vegan R Package v. 2.4-1. CRAN. R-project.org/package=vegan [accessed 10 July 2019].

Ostfeld, R.S. \& Holt, R.D. (2004) Are predators good for your health? Evaluating evidence for top-down regulations of zoonotic disease reservoirs. Frontiers in Ecology and the Environment, 2, 13-20.

Pita, R., Mira, A., Moreira, F., Morgado, R. \& Beja, P. (2009) Influence of landscape characteristics on carnivore diversity and abundance in Mediterranean farmland. Agriculture, Ecosystems and Environment, 132, 57-65.

Power, A.G. (2010) Ecosystem services and agriculture: tradeoffs and synergies. Philosophical Transactions of the Royal Society B: Biological Sciences, 365, 2959-2971.

Purvis, A., Gittleman, J.L., Cowlishaw, G. \& Mace, G.M. (200o) Predicting extinction risk in declining species. Proceedings of the Royal Society B: Biological Sciences, 267, 1947-1952.

R Core TeAm (2018) R: a Language and Environment for Statistical Computing. R Foundation for Statistical Computing, Vienna, Austria.

RAndA, L.A. \& Yunger, J.A. (2006) Carnivore occurrence along an urban-rural gradient: a landscape-level analysis. Journal of Mammalogy, 87, 1154-1164.

Rovero, F. \& Marshall, A.R. (2009) Camera trapping photographic rate as an index of density in forest ungulates. Journal of Applied Ecology, 46, 1011-1017.
Sanderson, J., Sunquist, M.E. \& Iriarte, A.W. (2002) Natural history and landscape-use of guignas (Oncifelis guigna) on Isla Grande de Chiloé, Chile. Journal of Mammalogy, 83, 608-613.

Schulz, J.J., Cayuela, L., Echeverria, C., Salas, J. \& Rey BenayAs, J.M. (2010) Monitoring land cover change of the dryland forest landscape of central Chile (1975-2008). Applied Geography, 30, 436-447.

Schüttler, E., Klenke, R., Galuppo, S., Castro, R.A., Bonacic, C., Laker, J. \& Henle, K. (2017) Habitat use and sensitivity to fragmentation in America's smallest wildcat. Mammalian Biology, $86,1-8$.

Silva-Rodríguez, E.A. \& Sieving, K.E. (2012) Domestic dogs shape the landscape-scale distribution of a threatened forest ungulate. Biological Conservation, 150, 103-110.

Silva-Rodríguez, E.A., OrtegA-Solís, G.R. \& Jimenez, J.E. (2007) Human attitudes toward wild felids in a human-dominated landscape of southern Chile. Cat News, 46, 19-21.

Silva-Rodríguez, E.A., Ortega-Solís, G.R., Jiménez, J.E. \& Sото-Gамвоа, M. (2009) Foxes, people and hens: human dimensions of a conflict in a rural area of southern Chile. Revista Chilena de Historia Natural, 82, 375-386.

Silva-Rodriguez, E.A., Ortega-Solís, G.R. \& Jiménez, J.E. (2010) Conservation and ecological implications of the use of space by chilla foxes and free-ranging dogs in a human-dominated landscape in southern Chile. Austral Ecology, 35, 765-777.

Silva-Rodríguez, E.A., Ovando, E., González, D., Zambrano, B., Sepulveda, M.A., Svensson, G.L. et al. (2018) Large-scale assessment of the presence of Darwin's fox across its newly discovered range. Mammalian Biology, 92, 45-53.

Simonetti, J.A. (1999) Diversity and conservation of terrestrial vertebrates in Mediterranean Chile. Revista Chilena de Historia Natural, 72, 493-500.

Simonetti, J.A. \& Mella, J.E. (1997) Park size and the conservation of Chilean mammals. Revista Chilena de Historia Natural, 70, 213-220.

Thorne, J.H., Cameron, D. \& Quinn, J.F. (2006) A conservation design for the central coast of California and the evaluation of mountain lion as an umbrella species. Natural Areas Journal, 26, 137-148.

VAnAk, A.T. \& Gompper, M.E. (2009) Dogs Canis familiaris as carnivores: their role and function in intraguild competition. Mammal Review, 39, 265-283.

Viers, J.H., Williams, J.N., Nicholas, K.A., Barbosa, O., Kotzé, I., Spence, L. et al. (2013) Vinecology: pairing wine with nature. Conservation Letters, 6, 287-299.

Wold A, H. (1981) Similarity indices, sample size and diversity. Oecologia, 150, 296-297.

Zúniga, A., Muñoz-Pedreros, A. \& Fierro, A. (2009) Uso de habitat de cuatro carnivoros terrestres en el sur de Chile. Gayana, 73, 200-210.

Zuur, A.F., Ieno, E.N., Walker, N.J., Saveliev, A.A. \& Smith, G.M. (2009) Mixed Effects Models and Extensions in Ecology with R. Springer, New York, USA. 